\section{Web of Science}

\section{Clarivate Analytics}

Search Search Results

Serviços $9^{\circ}$ a $\quad \square$ Export... Add to Marked List

\section{A GAMIFIED VIRTUAL LEARNING ENVIRONMENT FOR STATISTICS LEARNING}

By: Tenorio, MM (Tenorio, Marcos Mincov) ${ }^{[1]}$; Lopes, RP (Lopes, Rui Pedro) ${ }^{[2]}$; de Gois, LA (de Gois, Lourival Aparecido) ${ }^{[1]}$; dos Santos, G (dos Santos Junior, Guatacara) ${ }^{[1]}$

12TH INTERNATIONAL TECHNOLOGY, EDUCATION AND DEVELOPMENT CONFERENCE (INTED)

Edited by: Chova, LG; Martinez, AL; Torres, IC

Book Series: INTED Proceedings

Pages: 6248-6257

Published: 2018

Document Type: Proceedings Paper

\section{Conference}

Conference: 12th International Technology, Education and Development Conference (INTED)

Location: Valencia, SPAIN

Date: MAR 05-07, 2018

\section{Abstract}

Virtual Learning Environments (VLE) are web-based e-learning tools that provides support for students and teachers on the teaching-learning process. Although there are many VLE applications inside schools and universities, maximizing their efficiency is still a challenge. Nowadays, gamification has been a promising approach to overcome some limitations related to lack of motivation and contributing to improve students' involvement and engagement.

In this work, we combine gamification with VLE in the development of a gamified virtual learning environment. Game elements are integrated with digital content, with the purpose of improving the students' involvement, drawing their attention and motivating them to explore the learning activities. The platform is currently being used to support statistics learning in Higher Education, in two different countries: one in Portugal and the other in Brazil. The developed VLE allows teachers to manage both the content available to students and other learning activities, such as online tests or practical assignments. The actions performed by the students are monitored and experience points, badges and virtual currency are awarded according to several factors. Finally, the impact of the gamified virtual learning environment is assessed through several metrics and indicators in the code.

\section{Keywords}

Author Keywords: Gamification; Virtual Learning Environments; E-Learning

\section{Author Information}

Reprint Address: Tenorio, MM (reprint author)

+ Univ Tecnol Fed Parana, Curitiba, Parana, Brazil.

\section{Addresses:}

+ [1] Univ Tecnol Fed Parana, Curitiba, Parana, Brazil

+ [2] Inst Politecn Braganca, Braganca, Portugal

\section{Funding}

\begin{tabular}{|l|l|}
\hline Funding AgencyShow details & Grant Number \\
\hline CAPES & \\
\hline
\end{tabular}

View funding text

\section{Publisher}

IATED-INT ASSOC TECHNOLOGY EDUCATION \& DEVELOPMENT, LAURI VOLPI 6, VALENICA, BURJASSOT 46100, SPAIN

\section{Categories / Classification}

Research Areas: Education \& Educational Research

\section{Citation Network}

In Web of Science Core Collection

0

Times Cited

Create Citation Alert

\section{1}

Cited References

View Related Records

\section{Use in Web of Science}

Web of Science Usage Count

7

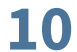

Last 180 Days

Since 2013

Learn more

This record is from:

Web of Science Core Collection

- Conference Proceedings Citation Index-

Social Science \& Humanities

\section{Suggest a correction}

If you would like to improve the quality of the data in this record, please suggest a correction. 
Web of Science Categories: Education \& Educational Research

See more data fields

\section{Cited References: 21}

2. El Curriculo de Estadistica en la Ensenanza Obligatoria

By: Batanero, C.; Arteaga, P.; Contrera, J. M.

EM TEIA Textbar Rev. Educ. Matematica E Tecnologica Iberoam Volume: 2 Issue: 2 Published: 2011

3. Title: [not available]

By: Batanero, C.; Diaz, C.

Estadistica con proyectos Published: 2011

Publisher: Departamento de Didfictica de la Matemitica, Granada

4. Title: [not available]

Times Cited: 1

By: Ben-Zvi, D.; Garfield, J.

The Challenge of Developing Statistical Literacy, Reasoning and Thinking Published: 2006

Publisher: Springer Science \& Business Media, Nederlands

5. Title: [not available]

Times Cited: 36

By: Brathwaite, B.; Schreiber, I.

Challenges for Game Designers Published: 2009

Publisher: Charles River Media Group, Boston (MA)

6. Mestrados academicos e doutorados no Brasil (2004 a 2014) da area ensino: temas para o ensino de probabilidade e estatistica

By: Bueno, A. J. A.; Ishikawa, E. C. M.; Junior, G. dos S.; et al.

Rev. Espac. Textbar Volume: 37 Issue: 21 Published: jul. 2016

Ano 2016

[Show additional data]

7. Gamification: toward a definition

Times Cited: 88

By: Deterding, S.; Khaled, R.; Nacke, L.; et al.

Chi Volume: 2011 Pages: 12-15 Published: 2011

URL: http://doi.org/978-1-4503-0268-5/11/0

[Show additional data]

8. Recursos Tecnologicos e Ensino de Estatistica na Educacao Basica: um cenario de pesquisas brasileiras

Times Cited: 1

By: Estevam, E. J. G.; Kalinke, M. A.

Rev. Bras. Informatica Na Educ Volume: 21 Issue: 02 Published: 2013

set

9. A multilevel analysis of the effects of external rewards on elementary students' motivation, engagement and learning in an educational game

By: Filsecker, Michael; Hickey, Daniel Thomas

COMPUTERS \& EDUCATION Volume: 75 Pages: 136-148 Published: JUN 2014

10. Importancia da Estatistica para o Processo de Conhecimento e Tomada de Decisao

Times Cited: 1 By: Ignacio, S. A.

Rev. Parana. Desenvolv.-RPD Issue: 118 Pages: 175-192 Published: fev. 2012

vol. 0 
11. Considerations on Gamification of E-Learning Application Case study with Phrase Building Training Application

By: Leee, Sungyoung; Lim, Sora

2014 6TH INTERNATIONAL CONFERENCE ON MULTIMEDIA, COMPUTER GRAPHICS AND BROADCASTING (MULGRAB) Pages: 55-58 Published: 2014

12. $A B C$ of learning and teaching - Web based learning

Times Cited: 124

By: McKimm, J; Jollie, C; Cantillon, $\mathrm{P}$

BRITISH MEDICAL JOURNAL Volume: 326 Issue: 7394 Pages: 870-873 Published: APR 192003

13. Title: [not available]

Times Cited: 6

By: Nielsen, J.; Loranger, $\mathrm{H}$.

Usabilidade Na Web Published: 2007

Publisher: Elsevier Brasil

14. A discussion on introducing half-anonymity and gamification to improve students' motivation and engagement in classroom lectures Times Cited: 7 By: Ohno, A.; Yamasaki, T.; Tokiwa, K.-I.

2013 IEEE Region 10 Humanitarian Technology Conference (R10-HTC) Pages: 215-20 Published: 2013

15. Digital Natives, Digital Immigrants

Times Cited: 4,124

By: Prensky, M.

Horizon Volume: 9 Issue: 5 Pages: 1-6 Published: 2001

16. Our Brains Extended

Times Cited: 10

By: Prensky, Marc

EDUCATIONAL LEADERSHIP Volume: 70 Issue: 6 Pages: 22-27 Published: MAR 2013

17. Designing for fun: how can we design user interfaces to be more fun?

Times Cited: 69

By: Shneiderman, B.

Interactions Volume: 11 Pages: 48-50 Published: 2004

18. Title: [not available]

Times Cited: 54

By: Sommerville, I.

Translator(s): Bosnic, Ivan; Goncalves, Kalinka G. de O.

Engenharia de Software Published: 2011

revisao tecnica Kechi Hirama

Publisher: Pearson Prentice Hall, Sao Paulo

19. Title: [not available]

Times Cited: 1

By: Sun, W.; Zhang, W.

The Research of Collaborative E-learning System towards Knowledge Management Pages: 354-357 Published: 2008

20. Elements of Gamification in Virtual Learning Environments: A Systematic Review

Times Cited: 1

By: Tenorio, M.; Reinaldo, F.; Gois, L.; et al.

P 20 INT C INT COLL Volume: 716 Published: 2017

[Show additional data]

21. Moodle: Moda, Mania ou Inovacao na Formacao?

Times Cited: 1

By: Valente, L.; Moreira, P.; Dias, P.

Moodle: estrategias pedagogicas e estudo de caso Pages: 35-54 Published: 2009

Publisher: Universidade do Estado da Bahia, Slavador

\section{Showing 21 of $21 \quad$ View All in Cited References page}

Clarivate

Accelerating innovation (c) 2020 Clarivate Copyright notice Terms of use Privacy statement Cookie policy 


\title{
A GAMIFIED VIRTUAL LEARNING ENVIRONMENT FOR STATISTICS LEARNING
}

\author{
Marcos Mincov Tenório', Rui Pedro Lopes², Lourival Aparecido de Góis', \\ Guataçara dos Santos Junior ${ }^{1}$ \\ ${ }^{1}$ Universidade Tecnológica Federal do Paraná (BRAZIL) \\ ${ }^{2}$ Instituto Politécnico de Bragança (PORTUGAL)
}

\begin{abstract}
Virtual Learning Environments (VLE) are web-based e-learning tools that provides support for students and teachers on the teaching-learning process. Although there are many VLE applications inside schools and universities, maximizing their efficiency is still a challenge. Nowadays, gamification has been a promising approach to overcome some limitations related to lack of motivation and contributing to improve students' involvement and engagement.

In this work, we combine gamification with VLE in the development of a gamified virtual learning environment. Game elements are integrated with digital content, with the purpose of improving the students' involvement, drawing their attention and motivating them to explore the learning activities. The platform is currently being used to support statistics learning in Higher Education, in two different countries: one in Portugal and the other in Brazil. The developed VLE allows teachers to manage both the content available to students and other learning activities, such as online tests or practical assignments. The actions performed by the students are monitored and experience points, badges and virtual currency are awarded according to several factors. Finally, the impact of the gamified virtual learning environment is assessed through several metrics and indicators in the code.
\end{abstract}

Keywords: Gamification, Virtual Learning Environments, E-Learning.

\section{INTRODUCTION}

Virtual Learning Environments (VLE) provide an online teaching-learning environment that allows the students to go through the subjects in their own rhythm and time restrictions with a high degree of autonomy. These environments allow the definition, management and access to educational activities, with a content and learning experiences management section for teachers and remote access to students [1].

VLE also provides a familiar environments to digital native students, with technology supporting their access to digital content, to teaching-learning activities, and other teacher mediated tools [2].

Although VLE are presented as an educational strategy to encourage students and involve them into the process of knowledge construction, nowadays, it still represents a challenge [3]. The teachinglearning environment in online resources, such as the ones provided by VLE, requires that students are autonomous and assume an active role in the development of their own knowledge. Teachers, instead of transmitting knowledge as in traditional classes, assume a moderation role, promoting the development of meaning within the students. This requires a high degree of motivation which, sometimes, is not present. Gamification is an approach that can improve the students' motivation, thus addressing this challenge, suggesting that the involvement in on-line environments will benefit [4]-[6].

Our proposal is to associate the features of a VLE with gamification, in the development of a custom platform that combines some aspects of both tools. The development of this platform should follow a rigorous methodology for software development, considering, at all times, the requirements of the software, the abilities of students and the full set of features.

This paper presents a software architecture of a gamified virtual learning environment that enables students to perform educational activities and appeal to high engagement levels, teachers to manage the content and the students' progress, and to extract and analyse data provided by the VLE. To implement these functionalities a software architecture was built with a set of business rules split into four main components: Students, Teachers, Teaching-Learning Experiences and Gamification. 
Finally, the deployment of this VLE is being done in Probability and Statistics learning, in Higher Education. The lack of virtual tools supporting the learning of this domain motivate this work. Here, the VLE will be used to support statistics learning in two countries: Portugal and Brazil.

\section{FROM STATISTICAL LEARNING TO GAMIFIED VIRTUAL LEARNING ENVIRONMENTS}

In recent years, fostered by technological development, there are significant changes in cultural, economic and social aspects of the society. Nowadays, the information holds a significant value. This made the statistics field a fundamental tool to several knowledge areas, being used to analyse data from different sources and creating useful knowledge [7]. Based on its importance, some authors suggest that statistics should not be limited to a scholar content but it should be used in our everyday practice [8]. Therefore, understanding and being able to use statistical theories and calculations is a condition to apply the knowledge in many scientific fields [8].

However, there are still a difficulty in fulfilling this. Although statistics learning is applied since primary school, even in higher education statistics learning is seen as a problematic issue and the students growing inability to perform statistical analysis is still a problem [9]. There is a challenge to teachers and researchers of promoting efforts to favor the learning of this field, especially on higher education. Some authors suggest that students success is improved when combining the theory, experiments and computational resources [10]. However, there is still a lack of studies relating Information and Communication Technology (ICT) applied to statistical learning [11].

In this context, Virtual Learning Environments (VLE) explore ICT to foster statistics learning. A VLE combines Information and Communication Technology with educational scenarios, creating learning environments and enabling their access from anywhere, at any time through the Internet [12]. The time and space flexibility helps students to access resources, thus motivating them to try these kind of platforms [13] [14]. However, students must also be stimulated to spend more time and energy in the learning process, because of the increasing active role they have to assume.

Gamification, defined as "the use of game design elements in non-game contexts", promises to increase the involvement of users in online environments [15]. Game elements are associated with game mechanics to motivate the student to advance the exploration and use of the environment. In other words, elements can be defined as a toolbox, to be used individually or combined [16]. Then, game design elements wrap up these elements into a systematic and artistic design. Finally, non-game contexts represent the purposes of the system, that is different from traditional game objectives, going beyond fun and entertainment [15].

Increasing the involvement of users can have positive effects in educational environments, drawing attention of the students towards a topic or subject. However, gamifying an educational environment does not consist in creating an educational game. It consists in the insertion of game elements and design to motivate and improve positive behaviors. In such cases, gamification is presented as an important approach for learning scenarios [17]-[19]. Finally, combining VLE with Gamification approach can provide positive outcomes and support statistical learning.

\section{PROPOSED ARCHITECTURE}

The aim of this paper is to develop an architectural project of a Virtual Learning Environment combined with gamification elements to provide a behavioural change on statistics students. The proposed architecture aims primarily at increasing students' involvement and, at the same time, allowing teachers to control and evaluate the student's development and provide effective assessments. This software development follows a theoretical model, based on a set of business rules that was defined in each component. The following subsections presents the developed model, the rules and their interactions in a specific scenario.

\subsection{Architectural Diagram}

First, a general architecture was proposed (Figure 1). This architecture consists of three layers based on an Model View Controller (MVC) model: user interface, representing the layer that controls the user's interaction with the system (view); the mediator between the user interface and de model, responsible for system communication with the user and the supervision of system's specific tasks (controller); and the data model, usually stored in a database (model). 


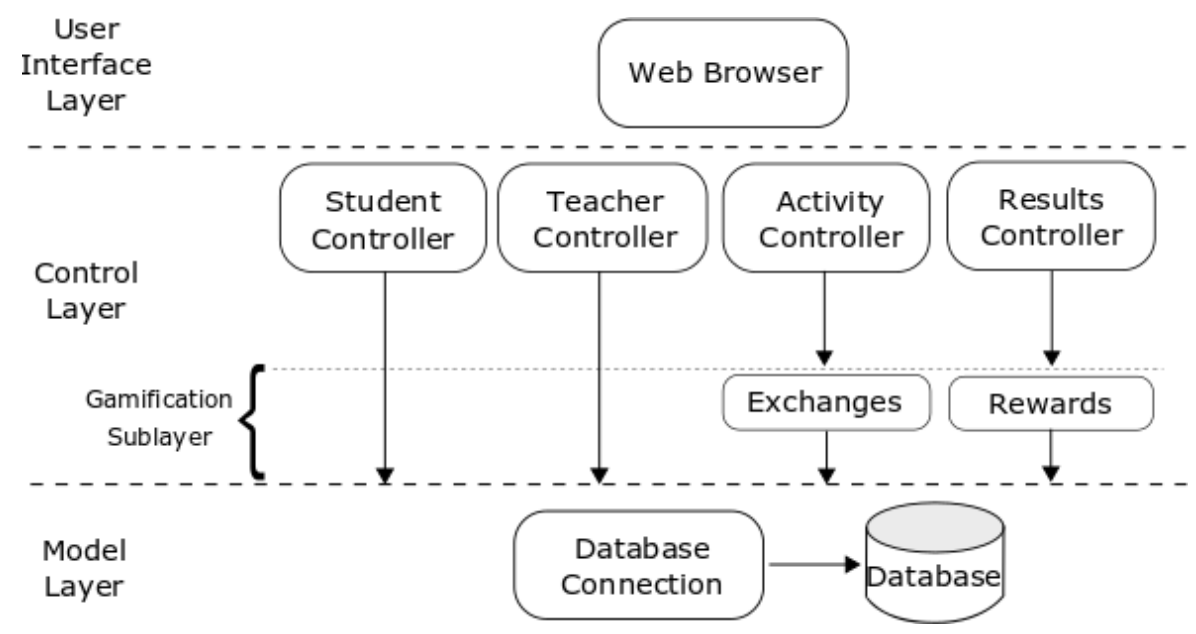

Figure 1. Architectural Diagram

In the User Interface Layer, the Web Browser is defined as the component in which the users access the environment. Seen as a web-based application, this VLE must be accessed through several platforms connected through the web.

The Control Layer holds the controllers for the student, teacher, teaching-learning activities (activity and results controller) and gamification elements. Each controller manages different parts of the VLE and apply rules defined in the following sections. Overall, the Students Controller implements the students' actions and manage their choices. This controller also collects metrics related to the participation, use and interactions between students within the VLE, for future evaluations. The Teacher Controller implements an independent access to the VLE, allowing the teachers to insert new content, exercises and manage the students' overall performance. The Activity Controller and Results Controller registers the attempts of students in solving the teaching-learning activities and perform the calculation of the students' performance. These controllers are connected with Gamification Sublayer, that defines the game rules and hold the responsibility to perform students' exchanges and calculate their rewards.

Finally, the Model Layer provides the access to data through Database Connection. This allows the storage of all VLE data and provide future access and searches.

\subsection{Components and Rules}

Beyond the architectural design, some important components were extracted from the general structure and a set of rules was established to regulate their operation. The following rules act as guidelines to software development and identifies some behaviours that gamification tries to explore.

\subsubsection{User - Students:}

- The students' role in the VLE is to register, access the content and perform the teaching-learning activities;

- To perform an activity, the student selects two parameters: content and difficulty;

- The students are free to select any content or difficulty related to the class;

- The students can perform unlimited attempts to solve the activity;

- The students receive feedback from their performance after completing the activities;

- All students' actions are registered for ongoing and future analysis.

\subsubsection{User - Teachers:}

- The teachers' role in the VLE is to create and manage digital content;

- The teachers create exercises containing a question, alternatives, difficulty and content;

- The teachers can access single student results from activity attempts;

- The teachers can access the final results from all activity tests.

\subsubsection{Teaching-learning Activities:}

- A teaching-learning activity comprises a set of four exercises, randomly retrieved from the database, and related to a content and difficulty (since they are randomly selected, each attempt contains, probably, a different set of exercises); 
- There are three difficulties in each activity (1: easy; 2 : regular; 3 : hard).

- Each activity has limited time defined by the difficulty (1:20'; 2: 40'; 3:60');

- The feedback results present the student's performance in the attempt;

- The final Score is in percent values and calculated through the Equation 1, in which: $E$ is the percent result of each exercise inside the Activity Test;

$$
\text { Score }(\%)=\frac{E_{1}+E_{2}+E_{n}}{n}
$$

- Each exercise $(E)$ is a problem categorized within a content and difficulty, stored in the system's database by teachers;

- The problem contains a question and a set of alternatives (multiple choice or true-false).

- The Exercise Score $\left(E_{i}\right)$ is a percentage. For multiple choice exercise, there are only two possible results: $E_{i}\{0,1\}$. For true-false exercises, the result is obtained through Equation 2, in which $A$ represent the result of each alternative (1: correct; 0 : wrong), $m$ is the total number of alternatives.

$$
E_{i}(\%)=\frac{A_{1}+A_{2}+A_{m}}{m}
$$

\subsubsection{Gamification elements:}

- The Gamification role is to involve and engage students creating a scenario based on game elements;

- Based on previous work, we select two core gamification elements, namely Experience Points and Virtual Currency [19]. Experience Points (EXP) represent the student's overall performance. Virtual Currency (eCoins) represent an exchangeable value, that can be converted in further opportunities for the student to successfully overcome an activity;

- The students collect the elements after performing an activity and the collected amount is strongly related to the student's performance;

- The calculation of the EXP and eCoin is given in Table 1, in which: Score is the performance in the activity (defined in section 3.2.3), diff is the difficulty parameter for the activity. The values are collected accordingly to the number of attempts inside each difficulty;

- Each attempt in the chosen difficulty parameter result in different values of EXP and, consequently, different values of eCoins;

- In an attempt, the student can perform trades using his eCoins. There are two available trade scenarios: removal of one question from the activity test; removal of some alternatives from the questions. The removal scenarios present different costs, according to the activities' difficulty, given in Table 2.

Table 1. Calculation of gamification elements after the students perform an activity.

\begin{tabular}{c|c|c}
\hline \hline Attempts inside each difficulty & EXP achieved & \multirow{2}{*}{ eCoin achieved } \\
\cline { 1 - 2 } Attempt $=1$ & $E X P=$ Score $\times$ diff & \multirow{2}{*}{ eCoin $=\left(\frac{E X P}{10}\right) \times$ diff } \\
\cline { 1 - 2 } Attempt $=2$ & $E X P=$ Score $\times 0.6 \times$ diff & \\
\cline { 1 - 2 } Attempt $=3$ & $E X P=$ Score $\times 0.3 \times$ diff & \\
\cline { 1 - 2 } Attempt $\geq 4$ & $E X P=$ Score $\times 0.1 \times$ diff &
\end{tabular}

Table 2. Trades cost in eCoins values.

\begin{tabular}{c|c|c|c|c}
\hline \multirow{2}{*}{ Difficulty } & \multicolumn{3}{|c|}{ Cost of alternatives removal } & \multirow{2}{*}{ Cost of question removal } \\
& One & Two & Three & \\
\hline 1 & 2 & 4 & 6 & 10 \\
\hline 2 & 3 & 6 & 9 & 15 \\
\hline 3 & 5 & 10 & 15 & 20 \\
\hline \hline
\end{tabular}




\subsection{Activity Diagram}

The above definitions and rules can be observed in an activity flow sequence through an Activity Diagram. This diagram present actions, transitions and decisions taken inside components when a student perform an activity attempt (Figure 2).

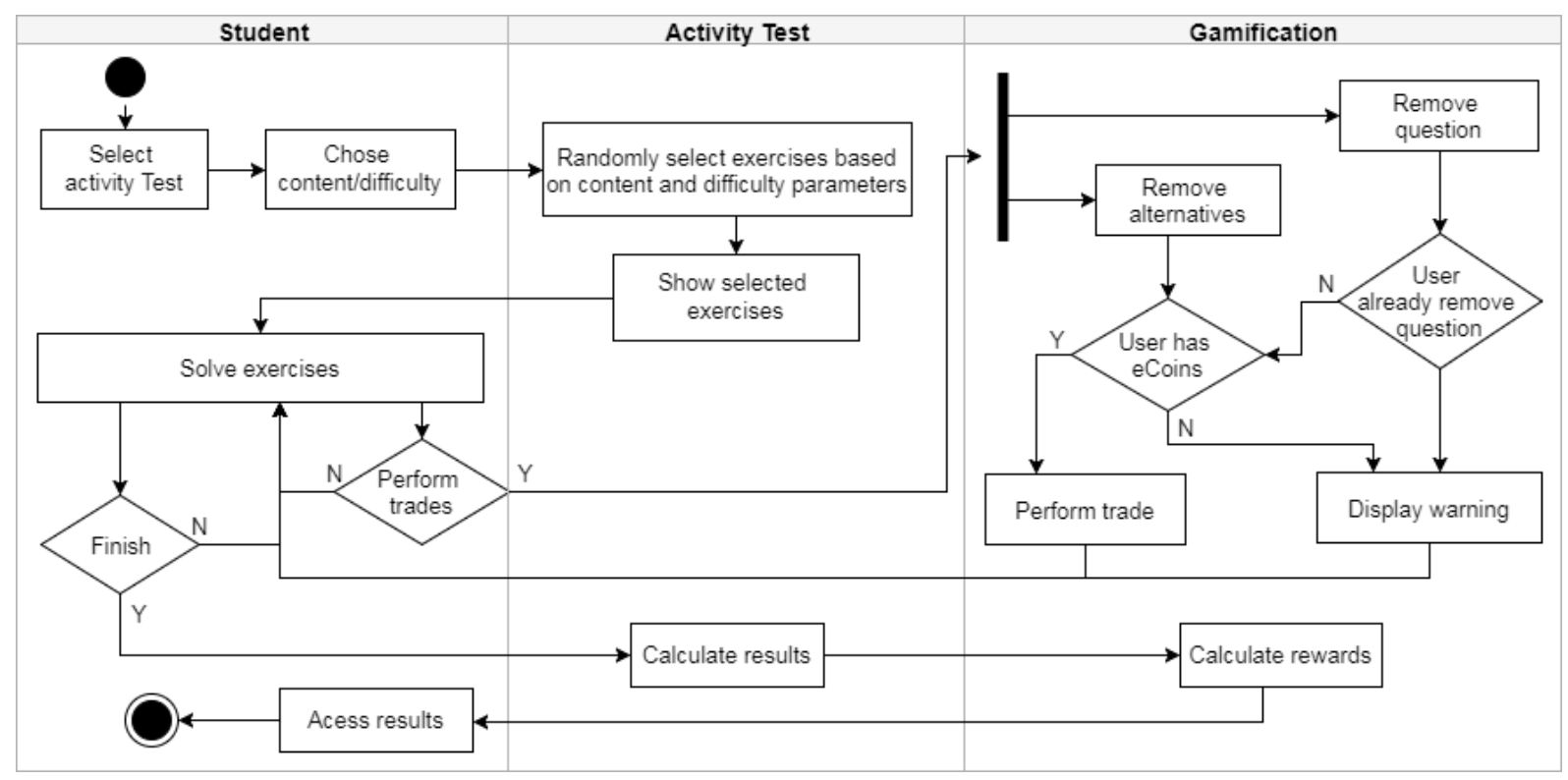

Figure 2. Activity Diagram of a Teaching-learning Activity.

Throughout the diagram, it is worth to note that, it is given to the student control of their choices and their actions, choosing initial parameters, trading eCoins, solving exercises and finishing the activity. The VLE controllers respond properly according to student choices and allow the gamification elements insertion.

\section{PRELIMINARY RESULTS}

The implementation of the previous rules in a VLE development resulted in the development of a system that combine interface design, modular components, data structure and algorithms. The development principles were based on Sommerville's best practices of software development [20].

The deployment was driven to support statistics learning in two different universities: the Polytechnic Institute of Bragança - Portugal (IPB) and the Federal University of Technology - Brazil (UTFPR). These two different scenarios were selected to provide future comparison relating students' involvement in the VLE.

\subsection{The VLE}

All VLE user interface elements were designed following Nielsen's design principles, prioritizing efficiency, productivity and satisfaction in the use [21]. Here, some graphical interface elements will be shown and the interface of the teaching-learning activity will be described.

First, the students access the VLE through an initial registration page, after which are given access to the course. After logging in, a timeline is presented to students containing all the recent actions and important information about the current course. In this page, a top bar shows the collected gamification elements, and a sidebar menu shows the functions offered in the VLE. These bars are also present in all students' screens (Figures 3 and 4).

To perform a teaching-learning activity, the student chooses the desired content and difficulty parameters. When the student starts the activity, several elements provide a real-time feedback guiding the student to perform the activity (Figure 3 ). 


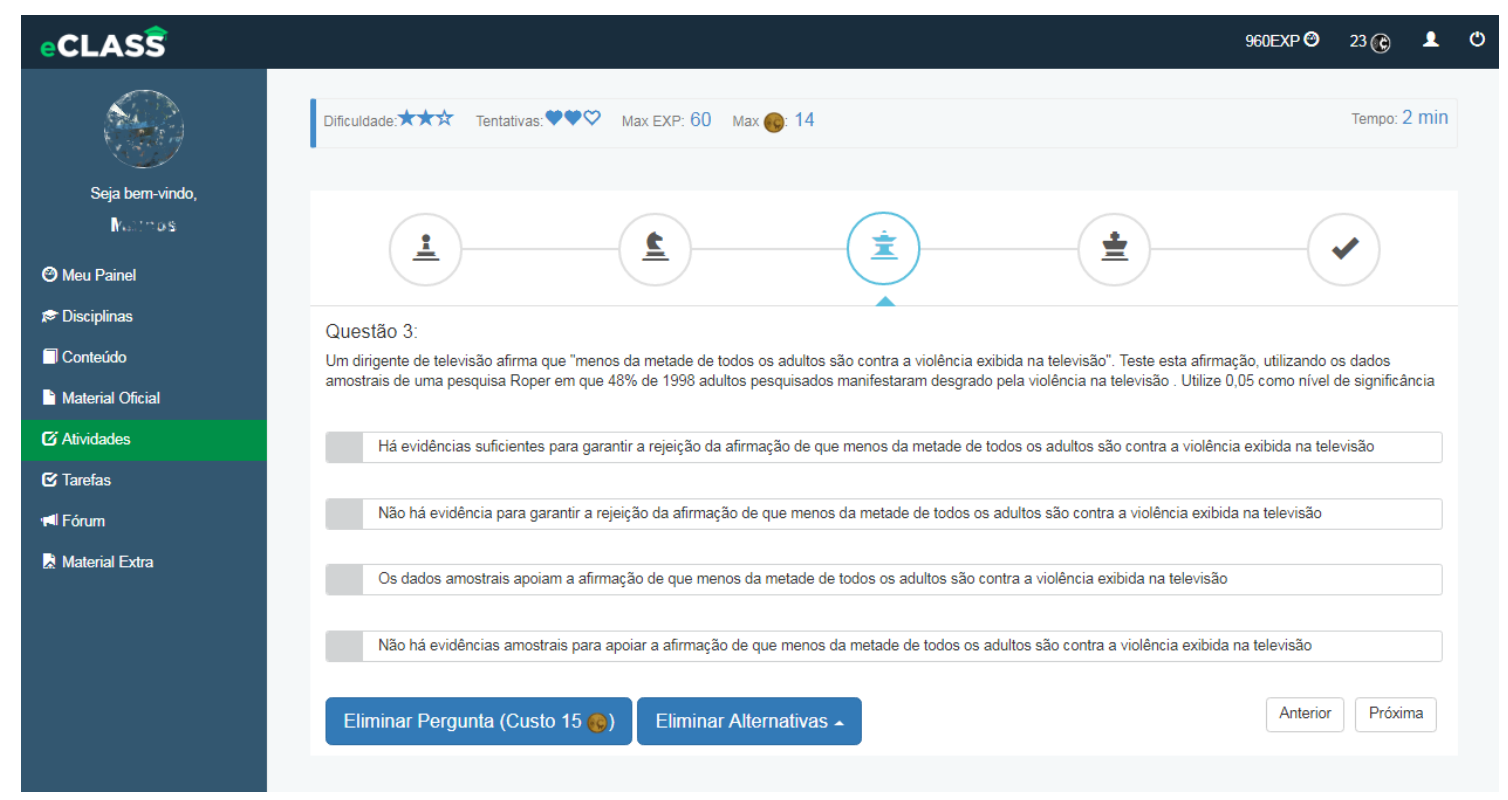

Figure 3. Teaching-learning activity screenshot.

In the teaching-learning activity screen, a bar on the top presents some gamification elements and parameters. These elements help the students to understand which activity they are currently working on and how much time is available. In the centre, students access the questions and alternatives. A navigation bar allows the access to all the activity's questions. Below, there are the trading area, in which students can choose to remove an entire question or alternatives from the question by spending some of the eCoins.

When the student completes the activity, a result screen is shown (Figure 4). This shows the activity performance (\%) in a progress bar, the collected EXP and eCoins, the difficulty parameter and the time spent on this activity.

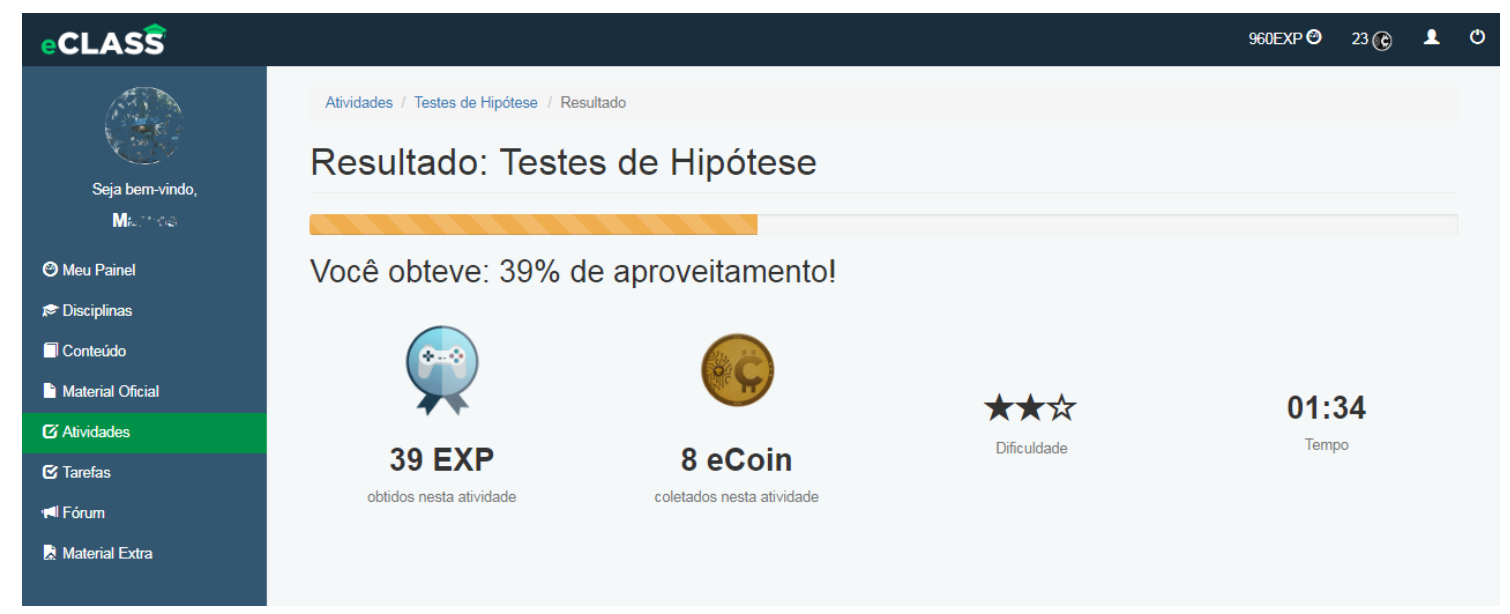

Figure 4. Activity results screenshot.

After completing the activity, students are free to choose other activities. They are encouraged to hit the maximum performance (100\%) on each content and difficulty of the teaching-learning activities.

The teacher's side, on the other hand, allows control and evaluation of the student's development. To access the VLE, the teacher receives a user login by the system's administrator.

First, the teachers must insert the questions (problems) using the VLE, in order to fulfil the required number of questions. A specific screen allows the insertion of the question text and alternatives, they also choose content and difficulty parameters. Then, teachers made available to students the activities and access their results (Figure 5). 


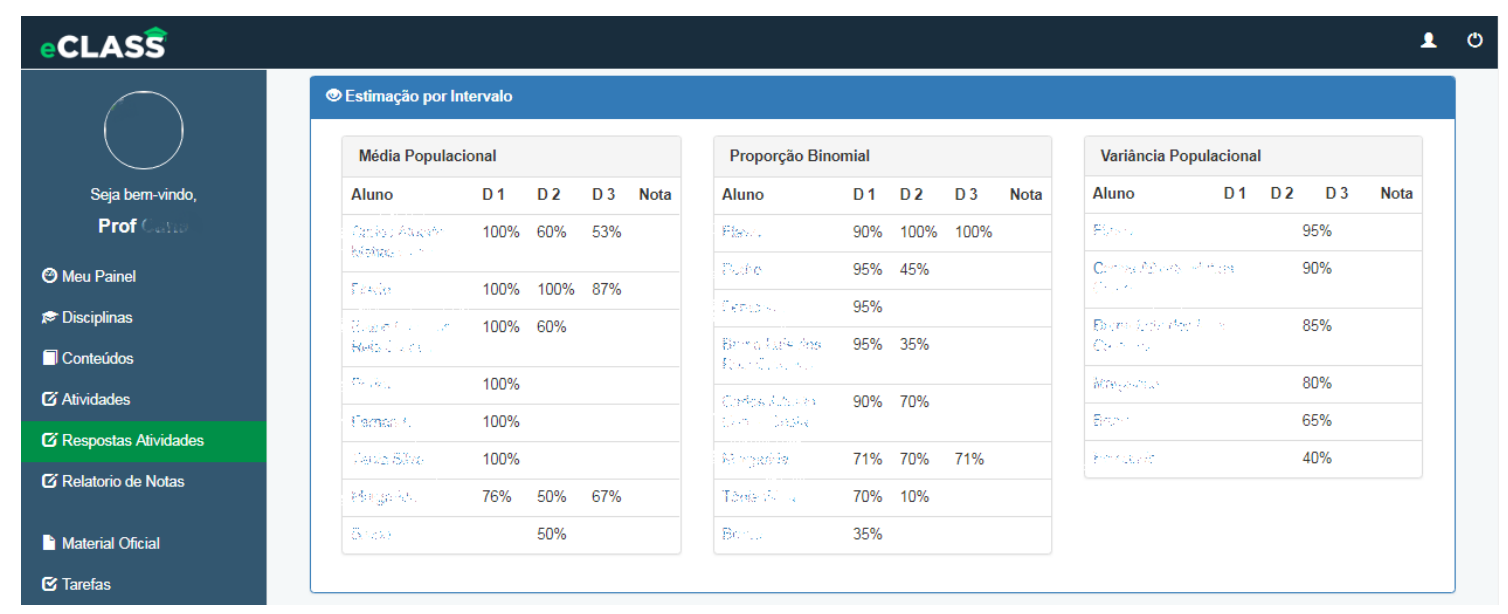

Figure 5. General results per content.

The general results show the top performance result per student, separated by content and difficulty parameters (Figure 5). Here, teachers can calculate the students' final score. Moreover, he can also identify where students had more difficulties and lower results. This information may support teachers to further improve the problems and the overall teaching-learning process.

Teachers can also access students' individual results. On the individual results screen can observe all the activities attempts, accessing all student's solved exercises and answers. Here, the teachers can track and guide individual cases, playing an important role on the students learning.

\subsection{Test Scenario}

The VLE is currently in production, being used by students in statistic learning classes. Some of the preliminary results from the IPB are already available. The class has 12 students, in a business management program. At the beginning of the semester, the teacher receives an initial support to insert the digital content and exercises and later inserted 175 exercises divided in 11 contents. Then, students received an initial training and clarification about the VLE and also received a digital version of the VLE user's guide.

Then, all VLE functions were fully available to students to perform their actions. The students could access through a web-browser using any platform (from desktop computer to mobile devices) at any time.

To this preliminary analysis we use the above scenario and collect basic usage data from an initial 30 day period. There was no intervention from researchers during this period.

\subsection{Collected Data}

Giving the fact that the VLE is currently in use, the data were collected from basic usage data (logs) to analyze initial behaviors towards the system. The logs extraction was possible due the rule defined in the subsection 3.2.1, in which proposes to monitor students' actions inside the VLE.

First, we collect the logs of the accesses (logins) and the number of activity attempts (Table 3 ). In this scenario, the Activity Tests were defined as the primary functionality of this VLE and the students' attempts here shows an initial indicator of students' engagement in a learning activity.

Table 3. Usage data

\begin{tabular}{c|c}
\hline \hline Number of Logins & 205 \\
\hline Activity Attempts & 805 \\
\hline Activities Concluded & 790 \\
\hline \hline
\end{tabular}

The number of logins is not very high. In average, each student performed 17 login operations, in the 30-days period. Nonetheless, it was not possible to estimate the amount of time spent on each login session and usually the web-browser preserves the section data, allowing the users to access the system several times without performing explicit login action. Due to this reason, we used other logs to draw more specific conclusions about the system usage. 
The number of activity attempts shows positive results giving an indication of the students' engagement. These reveal a positive outcome, confirming the importance of this teaching-learning activity to students.

We also collect gamification logs to assess if it helped the students to maintain high level of involvement. Here we observe each students' EXP, eCoins and trading (Table 4).

Table 4. Gamification logs for EXP, eCoins and trading

\begin{tabular}{c|c|c|c|c|c|c}
\hline \hline \multirow{2}{*}{$\begin{array}{c}\text { Student } \\
\text { ID }\end{array}$} & \multirow{2}{*}{$\begin{array}{c}\text { Activity Test } \\
\text { Attempts }\end{array}$} & EXP & \multicolumn{2}{|c|}{ eCoins } & \multicolumn{2}{c}{ Trades } \\
\cline { 3 - 7 } & Collected & Earned & Traded & Question & Alternatives \\
\hline 1 & 35 & 799 & 112 & 0 & 0 & 35 \\
\hline 2 & 93 & 2,688 & 475 & 22 & 0 & 93 \\
\hline 3 & 314 & 3,888 & 522 & 480 & 0 & 314 \\
\hline 4 & 8 & 336 & 33 & 0 & 0 & 8 \\
\hline 5 & 43 & 1,083 & 142 & 68 & 2 & 43 \\
\hline 6 & 117 & 3,574 & 649 & 530 & 1 & 117 \\
\hline 7 & 2 & 98 & 10 & 0 & 0 & 2 \\
\hline 8 & 0 & 0 & 0 & 0 & 0 & 0 \\
\hline 9 & 92 & 2,611 & 416 & 389 & 8 & 92 \\
\hline 10 & 63 & 1,180 & 148 & 86 & 0 & 63 \\
\hline 11 & 2 & 0 & 0 & 0 & 0 & 2 \\
\hline 12 & 36 & 1,421 & 174 & 45 & 0 & 36 \\
\hline Total & $\mathbf{8 0 5}$ & $\mathbf{1 7 , 6 7 8}$ & $\mathbf{2 , 6 8 1}$ & $\mathbf{1 , 6 2 0}$ & $\mathbf{1 1}$ & $\mathbf{8 0 5}$ \\
\hline \hline
\end{tabular}

First, the EXP element allows an initial analysis of student's engagement. The data shows that only a few students (3) collected under 100 EXP points and most of the students collected higher EXP number, seven of them above 1,000 EXP.

Then, eCoin element usage also shows the students' engagement and involvement in the VLE. Here students earn eCoins proportionately to the EXP values, with approximately $15 \%$ rate. This suggest that, initially, students tend to choose the 'easy' and 'regular difficulty', following the eCoin equation on Table 1.

After earning eCoins the students are able to exchange them (trading). Here, seven students performed this action and they spent, on average, $60 \%$ of their eCoin funds. This result suggests a significant usage of eCoins, showing that students understand the importance of this element. Meanwhile there are students that performed few trades, even holding a significant number of eCoins. This suggest that these students tend to save their eCoins for future opportunities or it can be a case in which they still did not understand the eCoins objective.

Observing the trades, there are a few 'question trades' when comparing to 'alternatives trades'. This may suggest that the cost of these trades (Table 2) might be balanced in future updates.

Overall, the usage data shows positive outcomes. In an initial 30-day scenario the collected data seems prominent and future results will allow to confirm some aspects related to students' involvement in the VLE. Besides, the gamification elements are fulfilling their desired role, involving students in learning activities, providing a feedback information about VLE usage and defining some students' behavior. Finally, when the VLE allow the data extraction it achieves the initial premise of allowing teachers to track students results and actions.

\section{CONCLUSIONS}

This paper proposes a combination of Gamification technique with Virtual Learning Environments that is being applied in statistics learning classes in Higher Education with the objective of providing to the students a learning environment that could improve their involvement.

The development started with the definition of an architecture, to guide the software implementation. A theoretical model was designed based on a set of business rules, defined for each component of the structure. We also added game elements in this architecture and provide a scenario to students explore 
learning activities through teaching-learning activities. Finally, we are currently using the VLE to support statistics learning in two Higher Education Institutions in Portugal and in Brazil.

We concluded that, using the proposed architecture it was possible to develop and deploy the Virtual Learning Environment in a statistics learning scenario. Preliminary results suggest that the actions performed by the students are successfully monitored supporting teachers to track and guide students in a correct learning path. The results also shown that gamification elements provide the desired feedback and we can observe the primary impact of the gamified virtual learning environment through metrics and indicators.

\section{ACKNOWLEDGEMENTS}

The research funding agency CAPES for the scholarships granted to the post-graduate student author of this study.

\section{REFERENCES}

[1] J. McKimm, "ABC of learning and teaching: Web based learning", BMJ, vol. 326, n 7394, p. 870873, abr. 2003.

[2] M. Prensky, "Digital natives, digital immigrants Part 1", Horiz., vol. 9, n 5, p. 1-6, 2001.

[3] L. Valente, P. Moreira, e P. Dias, “Moodle: Moda, Mania ou Inovação na Formação?”, in Moodle: estratégias pedagógicas e estudo de caso, Slavador: Universidade do Estado da Bahia, 2009, p. 35-54.

[4] A. Ohno, T. Yamasaki, e K.-I. Tokiwa, "A discussion on introducing half-anonymity and gamification to improve students' motivation and engagement in classroom lectures", in Humanitarian Technology Conference (R10-HTC), 2013 IEEE Region 10, 2013, p. 215-220.

[5] M. Filsecker e D. T. Hickey, "A multilevel analysis of the effects of external rewards on elementary students' motivation, engagement and learning in an educational game", Comput. Educ., vol. 75, p. 136-148, jun. 2014.

[6] S. Lee e S. Lim, "Considerations on Gamification of E-Learning Application: Case Study with Phrase Building Training Application", in 2014 6th International Conference on Multimedia, Computer Graphics and Broadcasting (MulGraB), 2014, p. 55-58.

[7] S. A. Ignácio, "Importância da Estatística para o Processo de Conhecimento e Tomada de Decisão", Rev. Parana. Desenvolv. - RPD, vol. 0, n 118, p. 175-192, fev. 2012.

[8] C. Batanero, P. Arteaga, e J. M. Contrera, "El Currículo de Estadística en la Enseñanza Obligatoria", EM TEIA Textbar Rev. Educ. Matemática E Tecnológica Iberoam., vol. 2, nº 2, 2011.

[9] D. Ben-Zvi e J. Garfield, The Challenge of Developing Statistical Literacy, Reasoning and Thinking. Nederlands: Springer Science \& Business Media, 2006.

[10] C. H. Barroqueiro, L. H. Amaral, e C. A. S. de Oliveira, "O Uso das Tecnologias da Informação e da Comunicação no Ensino de Ciências e Matemática", Tecnol. Cult., vol. 13, n 19, p. 45-58, mar. 2013.

[11] A. J. A. Bueno, E. C. M. Ishikawa, G. dos S. Junior, e M. M. Tenório, "Mestrados acadêmicos e doutorados no Brasil (2004 a 2014) da área ensino: temas para o ensino de probabilidade e estatística", Rev. Espac. Textbar Vol 37 No 21 Año 2016, jul. 2016.

[12] W. Sun e W. Zhang, "The Research of Collaborative E-learning System towards Knowledge Management", 2008, p. 354-357.

[13] C. Batanero e C. Diaz, Estadística con proyectos. Granada: Departamento de Didáctica de la Matemática Facultad de Ciencias de la Educación Universidad de Granada, 2011.

[14] M. Prensky, “Our Brains Extended”, Technol.-Rich Learn., vol. 70, nº 6, p. 22-27, mar. 2013.

[15] S. Deterding, R. Khaled, L. Nacke, e D. Dixon, "Gamification: Toward a definition", in CHI 2011 Gamification Workshop Proceedings, 2011, p. 12-15.

[16] B. Brathwaite e I. Schreiber, Challenges for Game Designers. Cengage Learning, 2009. 
[17] B. Shneiderman, "Designing for Fun: How Can We Design User Interfaces to Be More Fun?", interactions, vol. 11, n 5, p. 48-50, set. 2004.

[18] E. J. G. Estevam e M. A. Kalinke, "Recursos Tecnológicos e Ensino de Estatística na Educação Básica: um cenário de pesquisas brasileiras", Rev. Bras. Informática Na Educ., vol. 21, no 02 , set. 2013.

[19] M. Tenório, F. Reinaldo, L. Góis, R. P. Lopes, e G. Santos Junior, "Elements of Gamification in Virtual Learning Environments: A Systematic Review", in Proceedings of the 20th International Conference on Interactive Collaborative Learning, Budapest, 2017, vol. 716.

[20] I. Sommerville, Engenharia de Software, Edição: 9a. São Paulo: Pearson, 2011.

[21] J. Nielsen e H. Loranger, Usabilidade na web. Elsevier Brasil, 2007. 